\title{
Beyin Cerrahisi İçin Artırılmış Gerçeklik Uygulaması Gerçekleștirmek
}

\author{
Hasibe Nur Kılınç ${ }^{1 *}$, Yusuf Uzun ${ }^{2}$

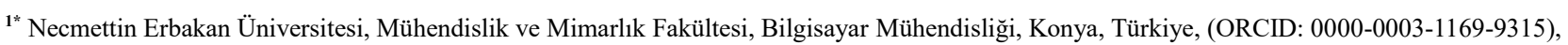 \\ hasibenurkilinc@gmail.com \\ ${ }^{2}$ Necmettin Erbakan Üniversitesi, Seydişehir Ahmet Cengiz Mühendislik Fakültesi, Bilgisayar Mühendisliği, Konya, Türkiye (ORCID: 0000-0002-7061-8784), \\ yuzun@erbakan.edu.tr
}

(İlk Geliş Tarihi 28 Aralık 2021 ve Kabul Tarihi 23 Ocak 2022)

(DOI: 10.31590/ejosat.1049487)

ATIF/REFERENCE: Kılınç, H.N. \& Uzun, Y. (2022). Beyin Cerrahisi İçin Artırılmış Gerçeklik Uygulaması Gerçekleştirmek. Avrupa Bilim ve Teknoloji Dergisi, (33), 290-296.

\section{Öz}

Son yıllarda tıp alanında Artırılmış Gerçeklik teknolojisi ile kaydedilen başarılar sayesinde kullanımına yönelik araştırmalar ve eğitim alanına yönelik araştırma sonuçları arasında ilk sıralara doğru önemli adımlar atılmaktadır. Bu çalışma beyin cerrahisi alanındaki tıp öğrencilerine ve öğreticilerine eğitimlerde kolaylık sağlamak amacıyla yapılmıştır. Bu çalışma Vuforia SDK, Visual Studio, İşaretçi ve Konum Tabanlı Artırılmış Gerçeklik Teknolojisi, Unity kullanarak hazırlanmıştır. Ayrıca bu çalışma sadece bilgi almak olarak değil bu sistemi kullanan öğrenci ve öğreticilerin katkılarıyla, bilgisi alınan ameliyatlar ve ders bileşenleri hakkında geri bildirimler ile tıp öğrencilerine daha iyi bir eğitim verebilecektir.

Artırılmış Gerçeklik teknolojisini ile yapılmış bu çalışma, beyin cerrahisi alanındaki tıp öğrencilerinin sadece teoriye bağlı kalmadan bu uygulama sayesinde daha fazla derse ve konuya odaklanmalarına izin verir. Artırılmış Gerçeklik, gerçek dünyaya sanal beyin diyagramları ve anatomisi ekledikçe, öğrencilerin uygulamadaki fiziksel cihazlar yardımıyla dersteki eğitmelerine izin vermektedir. Bu nedenle, sadece ders kitabını takip etmek veya dersi dinlemek yerine, uygulamada öğrenciler aslında kitaptaki bilgiler ile ameliyat zamanında oluşturulmuş videoları o kısımlarda izleyerek dersi pekiştirmelerine yardımcı olabilir ve derste pratik yapmaya başlayabilirler. Bundan dolayı, dersteki öğrencilerin öğrenme deneyimini geliştirir ve katılımı artırır.

Anahtar Kelimeler: Beyin Cerrahisi, Artırılmış Gerçeklik, AG.

\section{Developing Augmented Reality Application for Neurosurgery}

\begin{abstract}
Thanks to the successes recorded with Augmented Reality technology in the field of medicine in recent years, important steps have been taken towards the first place among researches on its use and research results in the field of education. This study was carried out to facilitate the training of medical students and instructors in the field of neurosurgery. This study was prepared using Vuforia SDK, Visual Studio, Pointer and Position Based Augmented Reality Technology, Unity. In addition, this study will not only provide information, but also with the contributions of students and instructors who use this system, with feedback on the surgeries and course components, which will provide a better education to medical students.

This study, made with Augmented Reality technology, allows medical students in the field of neurosurgery to focus on more lessons and topics thanks to this application, without depending only on theory. Augmented Reality allows students to train in the classroom with the help of physical devices in the app, as it adds virtual brain diagrams and anatomy to the real world. Therefore, instead of just following the textbook or listening to the lesson, in practice, students can actually help reinforce the lesson by watching the information in the book and the videos created during the surgery in those parts and start practicing in the lesson. Therefore, it improves the learning experience of students in the course and increases participation.
\end{abstract}

Keywords: Neurosurgery, Augmented Reality, AR.

\footnotetext{
*Sorumlu Yazar: hasibenurkilinc@gmail.com
} 


\section{Giriş}

Mobil ve kablosuz cihazların hızlı bir şekilde yaygınlaşması, Artırılmış Gerçeklik gibi yenilikçi bir teknolojinin eğitim ortamlarında kullanılmasına yardımcı olmaktadır. Bu teknolojiler, üç boyutlu (3D) çoklu ortam içeriklerini etkileşim, gerçeklik ve duyusal dalma konularında oldukça farklı boyutlara ulaştırmaktadır (Özdemir, 2017).

Artırılmış Gerçeklik teknolojilerinin sahip olduğu benzersiz etkileşim özellikleri sayesinde, öğrencilerde geleneksel yöntemler ile gerçekleştirmenin mümkün olmadığı bir takım özel becerilerin gelişimine olanak sağlanabilir (Özdemir, 2017).

Artırılmış Gerçeklik, bilgisayar donanım ve yazılımları yardımıyla bir araya getirilmesiyle oluşan görsellerin, 3D nesnelerin ve videoların gerçek ortamda birleştirilerek etkileşimli olarak gösterilmesi olarak da tanımlanabilir (Yolcu, Emre, \& Celayir, 2018).

Artırılmış Gerçeklik ile bir araya getirilen görüntüler gerçek ortamlarla birleşir ve oluşturulan videolar ve görüntüler o anda meydana getirilen gerçek ortamın bir parçası olarak görünmektedir. Bundan kaynaklı olarak turizm, tıp, sağlık, askeri, endüstri, inşaat ve eğitim gibi sektörlerde yaygın olarak kullanılmıştır.

Artırılmış Gerçeklik için öncelikle gerçek ortamda birleştirilecek video ve görüntüler uygulama yazılımlarıyla oluşturulur. $\mathrm{Bu}$ oluşturulan video ve görüntüler genellikle üç boyutlu nesnelerle oluşturulur (İçten \& Bal, 2017).

Oluşturulan görüntüler ve videolar ara uygulama ve programlara aktarılarak çeşitli GPS verileri ile işlenerek gerçek ortamla aynı çalışma haline getirilir. Oluşturulan görüntülerin öğrencilere aktarılabilmesi için de mobil telefonlar, tabletler veya teknolojik cihazlarla (Google Glass, Monte Gözlükler, Hololens gibi vb. cihazlarla) kullanılır hale getirilir (İçten \& Bal, 2017).

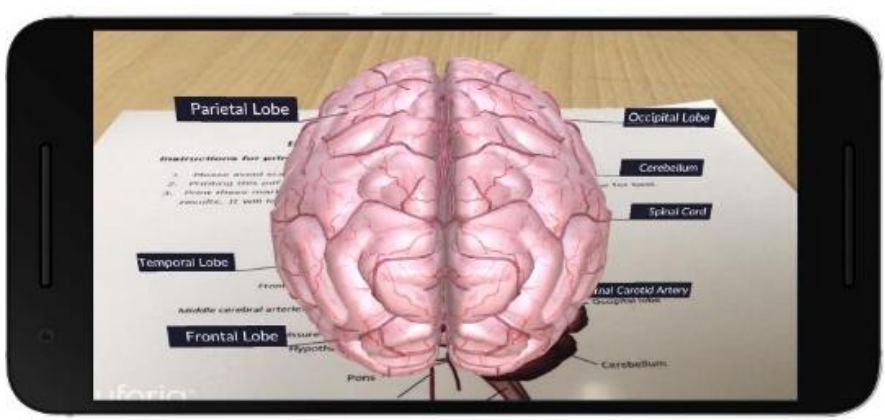

Şekil 1. Beyin Cerrahisinde AG 3D İnsan Beyni Modeli (Figure 1. AG 3D Human Brain Model in Neurosurgery)

Artırılmış Gerçeklik' in Tıp alanındaki kullanım alanlarını şöyle sıralayabiliriz;

1-Klinik ve günlük uygulamalarda

2- Eğitim ve akademik yayınlarda

3-Ameliyatlarda

4-Hasta ve hasta yakınlarına bilgi vermekte kullanılabilir.
Artırılmış Gerçekliği tıp eğitiminde kullanılmasını klinik eğitimde ve öğrenci eğitiminde kullanabiliriz (Yolcu, Emre, \& Celayir, 2018).

Bu çalışmada Artırılmış Gerçeklik teknolojisinin teknolojik cihazlardaki öğrenme yaklaşımının eğitimdeki faydalarından yararlanarak beyin cerrahisindeki tıp öğrencilerinin ve öğreticilerinin derslerdeki öğrenimde bu çalışmanın kullanılması için odaklanılmıştır.

Böylece tıp fakültesi öğrencilerin dersleri yoğun bilgi ve tıp terimleri içerdiği için öğrencilere aktarılması mümkün olmamaktadır. Bundan dolayı tıp öğrencilerinin ders dışında da konuyla ilgili çalışmaları gerektiğinde herhangi bir kamerası olan bir cihazdan veya NFCI kartlarını okutarak uygulamalara erişerek dersle ilgili kısımların 3d nesnelerini, videolarını, ameliyatlarını inceleme imkânı sağlamaktadır.

$\mathrm{Bu}$ doğrultuda uygulamada teknolojik cihazlardan öğrenme yaklaşımıyla tıp öğrencilerine ve öğreticilerine her an her yerde öğrenme ve öğretme imkânı sunmaktadır. Böylelikle çoklu ortam materyallerinin teknolojik cihazlarının artırılmış gerçeklikle öğrenme yaklaşımıyla kitaplar ve sunumlarla birlikte kullanılmasıyla öğrenmenin daha hızlı algılayabilmelerine öğrencilere daha uygun bir çözüm sunmaktadır.

$\mathrm{Bu}$ çalışmada sadece bilgi almak olarak değil bu sistemi kullanan öğrenci ve öğreticilerin katkılarıyla, bilgisi alınan ameliyatlar ve ders bileşenleri hakkında geri bildirimler ile beyin cerrahisindeki tıp öğrencilerine daha iyi bir eğitim sunabilecektir.

Ayrıca ikinci bölümde kısaca Konum ve İşaretçi Tabanlı Artırılmış Gerçeklik Teknolojisi, Vuforia SDK, geliştirme ortamı olarak Unity, Android Studio ve Visual Studio kullanıldığ materyal ve metot kısmında vurgulanmıştır. Üçüncü bölümde yapılan uygulamada elde edilen görüntüler ve bilgiler bulgular kısmında vurgulanmaktadır. Dördüncü bölümde de çalışmada elde edilen sonuçlar ve sonuçların avantajları ve varsa dezavantajları vurgulanmıştır.

\subsection{Artırılmış Gerçeklik}

Artırılmış Gerçeklik uygulamalarında, kullanan teknolojiler kullanıldığında optik ve video temelli teknolojiler olmak üzere iki grupta ele alınabilir. Bu iki grup arasındaki farklılık sanal ve gerçek dünyanın bütünleştirilmesiyle oluşturulan alanın görüldüğü yerdir. Video temelli sistemlerde bütünleştirilmiş sahne teknolojik cihazlar (mobil, tablet, bilgisayar vb.) üzerinde, optik sistemlerde ise bütünleştirilmiş gözlüklerle gerçek dünyada görülmektedir (İçten \& Bal, 2017).

Artırılmış gerçeklik, öğrencilerin ve öğreticilerin öğrenme ortamları ve yaşadıkları gerçek dünyayı birleştirerek öğrenilen bilgi ve becerilerini uygulamalarına olanak sağlamaktadır. Öğrenen öğrencilerin grup içerisinde kendi bilgi ve deneyimlerini paylaşabilmelerinden dolayı artırılmış gerçeklik ortamlarında bilginin aktarımı imkânı sunulmuştur (Küçük, Kapakin, \& Göktaş, 2015). 


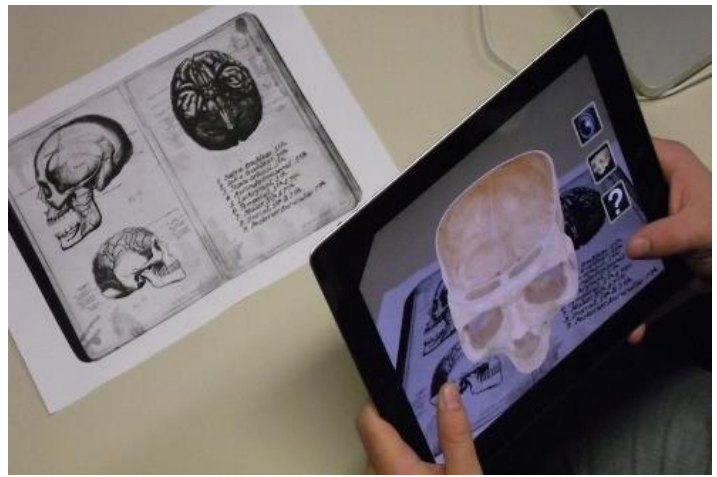

Şekil 2.Beyin Cerrahisi Eğitimde Artırılmış Gerçeklik

(Figure 2. Augmented Reality in Neurosurgery Education)

AG uygulamalarının gerçek ortamda gösterimi 3 şekilde yapılmaktadır. Bunlar işaretçi tabanlı, konum tabanlı ve işaretçisiz (markerless) olarak oluşturulmaktadır (Akkuş \& Özhan, 2017).

İşaretçi Tabanlı Artırılmış Gerçeklik Çalışmaları; gerçek ortamda bulunan bir görsel üzerine sanal materyallerin yerleştirilmesiyle oluşturulmaktadır. Görsellere bağlı çalışırlar. Tüm alanlarda en çok kullanılan yapıdır. Wikitude, Artoolkit, Vuforia, Layar vb. alan yapılarıyla kullanılmaktadır (Akkuş \& Özhan, 2017).

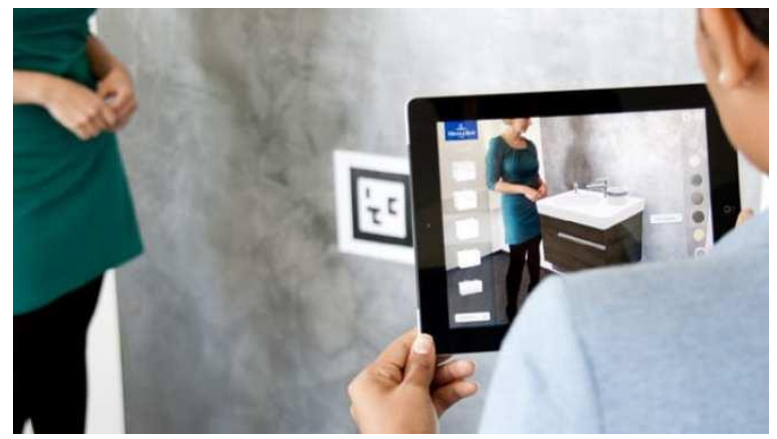

Şekil 3. İşaretçi Tabanlı Artırılmış Gerçeklik (Figure 3. Pointer Based Augmented Reality)

Konum Tabanlı Artırılmış Gerçeklik Çalışmaları; konum bilgilerinin kullanılarak sanal oluşturulan materyallerin belirli konumlarda tetiklenerek gerçek ortamda gösterilmesi şeklinde oluşturulmaktadır. GPS ve harita bilgilerini kullanır. Turizm alanlarında daha çok kullanılmaktadır. ARtoolkit 6 ve Wikitude yapılarıyla kullanılmaktadır (Akkuş \& Özhan, 2017).

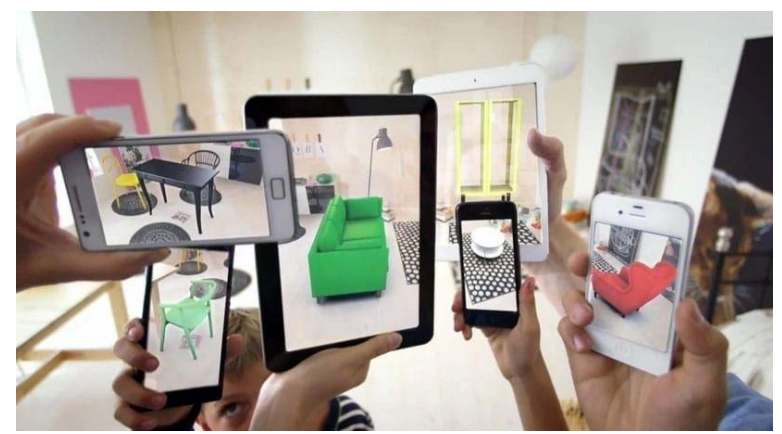

Şekil 4. Konum Tabanlı Artırılmış Gerçeklik (Figure 4. Location Based Augmented Reality)
İşaretçisiz (Markerless) Artırılmış Gerçeklik Çalışmaları; günümüzde yeni nesil optik tabanlı akıllı gözlüklerle birlikte kullanılmaktadır. Kullanıcıyı gerçek ortamda etkileşime dahil eder. Tıp, eğitim, sağlık, turizm vb. başta olmak üzere birçok alanda kullanılmaktadır. ARkit, Vuforia, Wikitude, ARtoolkit 6, ARcore, vb. yapılarıyla kullanılmaktadır (Akkuş \& Özhan, 2017).

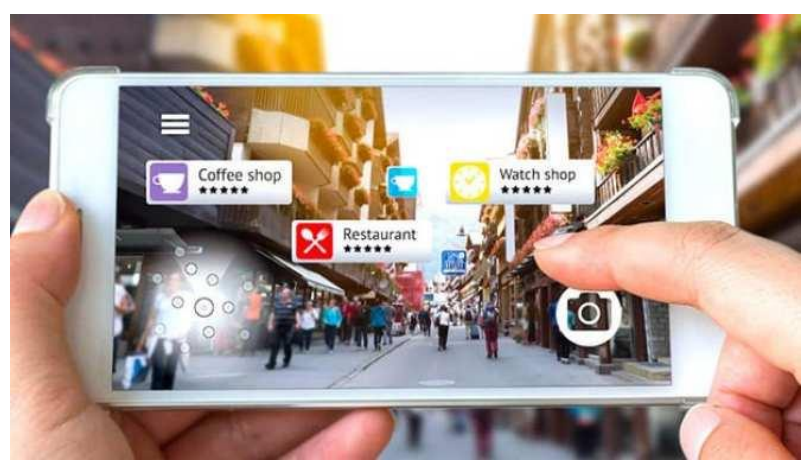

Şekil 5. Markerless Tabanlı Artırılmış Gerçeklik (Figure 5. Markerless Based Augmented Reality)

\subsection{Artırılmış Gerçeklik İçin Kullanılan Çevre Birimleri}

Artırılmış Gerçeklik için kullanılan çevre birimleri;

a) Donanımsal Çevre Birimleri

b) Yazılımsal Çevre Birimleri

c) Marker Çevre Birimleri

d)Artırılmış Gerçeklik Gözlükleri olarak sıralayabiliriz.

\subsubsection{Donanımsal Çevre Birimleri}

Artırılmış gerçeklikte tüm çalışmalar bilgisayar alt yapısı yardımıyla oluşturulmaktadır. Genellikle 3D modellerin gerçek alanlarda görüntülenebilmesi için uygulamanın hızı bakımından yüksek performanslı bilgisayarlara ihtiyaç duyulmaktadır. $\mathrm{Bu}$ teknolojinin genellikle mobil teknolojili uygulamalar üzerinde geliştirilirse; Artırılmış Gerçeklik teknolojisi için en önemli ihtiyacın donanım olduğu anlaşılabilmektedir. Bundan dolayı Ipad, PC, Notebook, kamera vb. cihazlar örnek verilebilir (Çakal \& Eymirli, 2012).

\subsubsection{Yazılımsal Çevre Birimleri}

Artırılmış gerçeklikte sanal ile gerçek ortamı birlikte yorumlayacak bir ara yardımcı yüzeye ihtiyaç vardır. Bu ara yüzey genellikle yazılım firmalarının lisanslı yazılım paketleri olarak piyasada bulunmaktadır. Genellikle bu yazılımlarda artırılmış gerçeklikte bir takım kolaylıklar sağlamak için oluşturulan araçlarla tasarlanmaktadır. $\mathrm{Bu}$ yazılımlar genelde mobil uygulama araçları, modelleme araçları, marker araçları, mobil uygulama araçları ve web ara yüzü geliştirme araçları ile oluşmaktadır (Akkuş \& Özhan, 2017).

\subsubsection{Marker Çevre Birimleri}

Gerçek ortamla sanal ortam arasındaki konumsal bağı markerlar oluşturmaktadır. Bu markerler ilk uygulandığ 1 yıllarda 2 bitlik şekillerde oluşturulurken şimdiki zamanlarda gerçek hayattaki herhangi bir nesne; işaretçi marker olarak kullanılmıştır (Çakal \& Eymirli, 2012). 


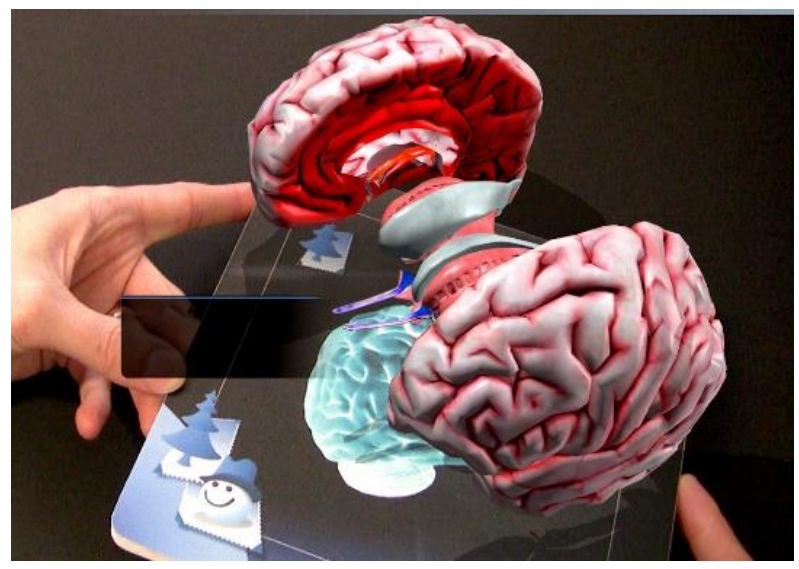

Şekil 6. Marker Çevre Birimleri (Figure 6. Marker Peripherals)

\subsubsection{Artırılmış Gerçeklik Gözlükleri}

Gerçek ile sanal ortam arasındaki verilerin ve görüntülerin oluşması ve uygulamayı kullanacak kişilerin sanal ile gerçeği birlikte algılayabilmesine imkân sunan gözlüklerdir (Çakal \& Eymirli, 2012).

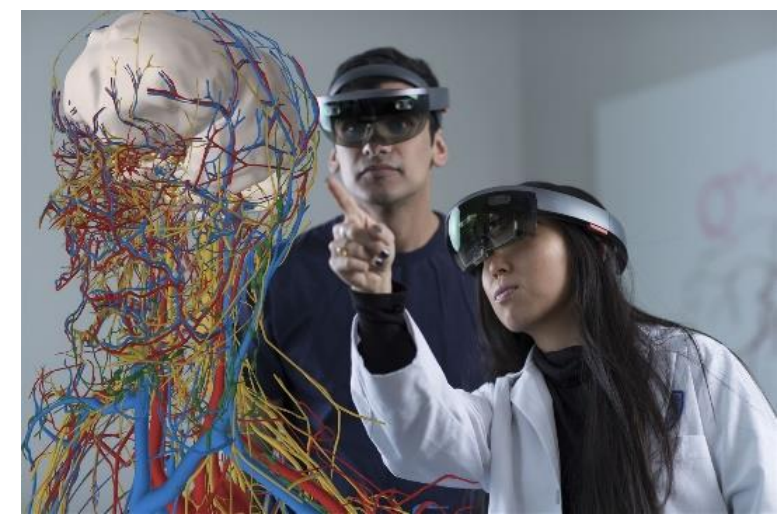

Şekil 7. Artırılmış Gerçeklik Gözlükleri (Figure 7. Augmented Reality Glasses)

\subsection{Artırılmış Gerçekliğin Endüstride Kullanımı}

Günümüzde Artırılmış Gerçeklik teknolojisi insanların, öğrencilerin ve iş liderlerinin ilgilenmeleri için ana araç haline geldi. Bu teknolojinin kullanıldığı bazı sektörler; inşaat, imalat, yiyecek ve içecek endüstrisi, pazarlama, eğitim, tıp vb.

\subsubsection{Inşaat}

Artırılmış gerçeklikte inşaatlar proje halindeyken müşterilerine inşaatların bitmiş hallerini göstererek dairelerini daha hızlı satmalarına yardımcı oluyor. Ev sahibi olacak kişiler 360 renderları artırılmış gerçeklik gözlükleriyle bitmiş hallerini inceleyerek firsatları yakalıyorlar ve 3D modeller üzerinden satın alabiliyorlar. Bu çalışmalar inşaat sektörüne büyük fayda sağlıyor (Bingöl, 2016).

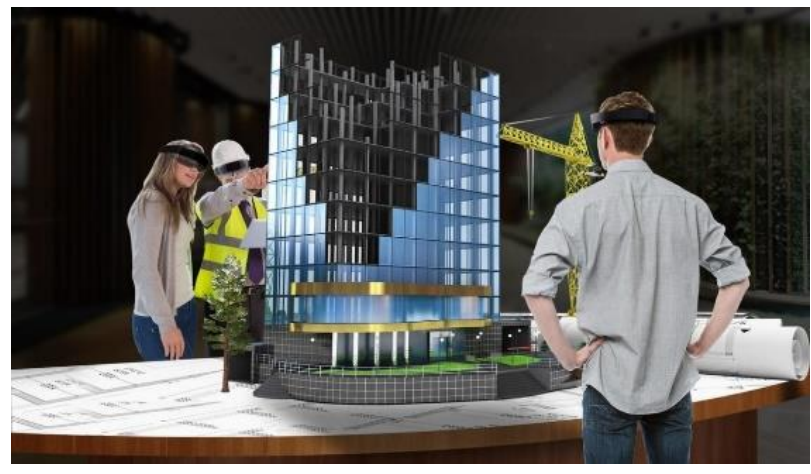

Şekil 8. İnşaat Sektöründe Artırılmış Gerçeklik (Figure 8. Augmented Reality in the Construction Industry)

\subsubsection{Imalat}

İmalat sektöründe geliştirme olan bir üründe hata yapmayı göze alamazsınız. Ürün prototipini 3 boyutlu olarak prototipe erişmeyi ve anlamayı kolaylaştırır. $\mathrm{Bu}$ süreçte iş dünyasındaki liderlerin ekiplerini doğru yönlendirme ve doğru karar verebilirler bu da sürecin hızlandırılmasını ve sonuçta ortaya çıkan kazancı ve deneyimi arttırır (arimarsc, 2019).

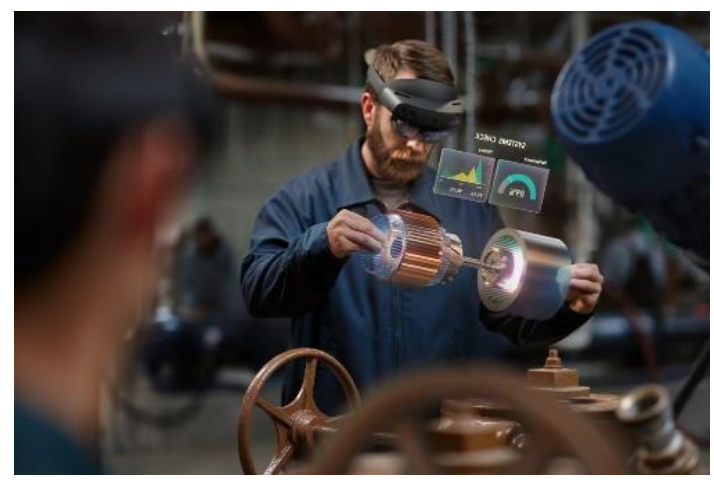

Şekil 9. İmalat Sektöründe Artırılmış Gerçeklik (Figure 9. Augmented Reality in the Manufacturing Industry)

\subsubsection{Yiyecek ve İçecek Endüstrisi}

Artırılmış Gerçeklikte Teknolojisinde, tüketicilerin sipariş ettikleri her gida ürünün görüntüsü, içeriğini ve kalorileri hakkında bilgi almalarını sağlamaktadır. Restoran veya cafe vb. mekanlarda müşterilerin seçimlerini uygulama vasıtasıyla 3D olarak görmeleri ve ürünün gelmeden nasıl olacağına dair fikir sahibi oluyorlar (Çakal \& Eymirli, 2012).

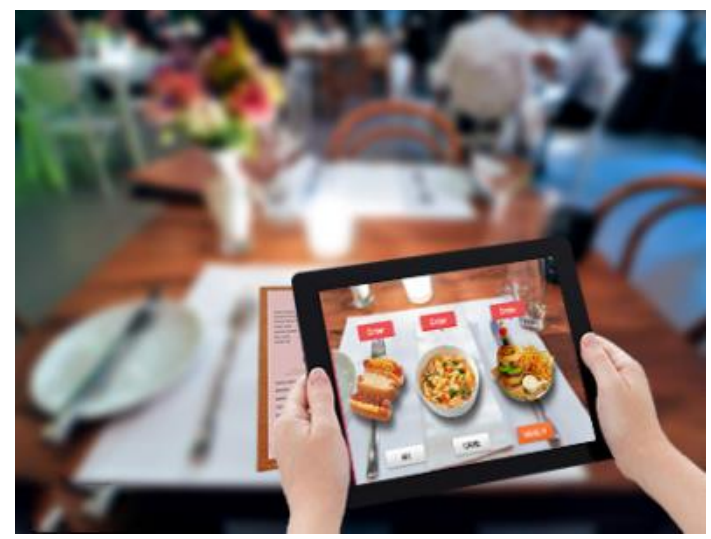

Şekil 10. Yiyecek ve İçecek Endüstrisi Artırılmış Gerçeklik (Figure 10. Food and Beverage Industry Augmented Reality) 


\subsubsection{Pazarlama}

Artırılmış Gerçeklik, Pazarlamacıların posterlerine, reklam, broşürlerine, el ilanlarına, tişörtlerine ve panolarına hedef tabanlı ek bilgiler, video ve 3B animasyonlar eklemelerine yardımc olmaktadır. Bundan dolayı, müşterilerine hatasız ve kazançlı bir tecrübe sunar (İçten \& Bal, 2017).

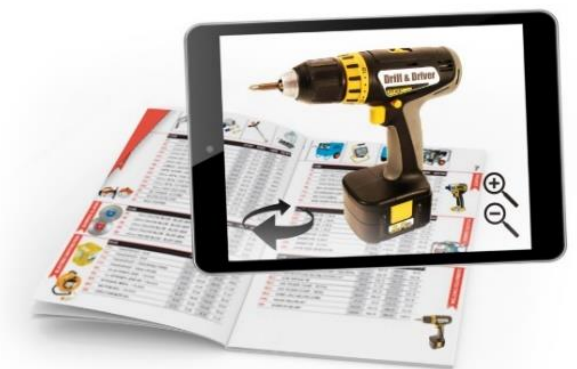

Şekil 11. Pazarlama Sektöründe Artırılmış Gerçeklik (Figure 11. Augmented Reality in the Marketing Industry)

\subsection{5. Ĕ̈itim}

Eğitim sektöründe öğrenci ve öğretmenlere kavramları ve bilgileri etkileşimli kılarak fark yaratıyor. 3B artırılmış gerçeklik 3d modellemesi ile sıkıcı bir dersi bir deneyime dönüştürerek ve karmaşık kavramları, bilgileri kolayca öğrenmelerine yardımcı oluyor. Ayrıca, öğretmenlerin öğrencilere en doğru şekilde çıktıları verebilmelerine ortam sağlıyor. Örneğin, geometri derslerindeki şekilleri uygulama vasıtasıyla öğrencilerin 3D göstererek geometriyi sevmelerini sağlayabilir (Güneş \& Dilipak, 2020).

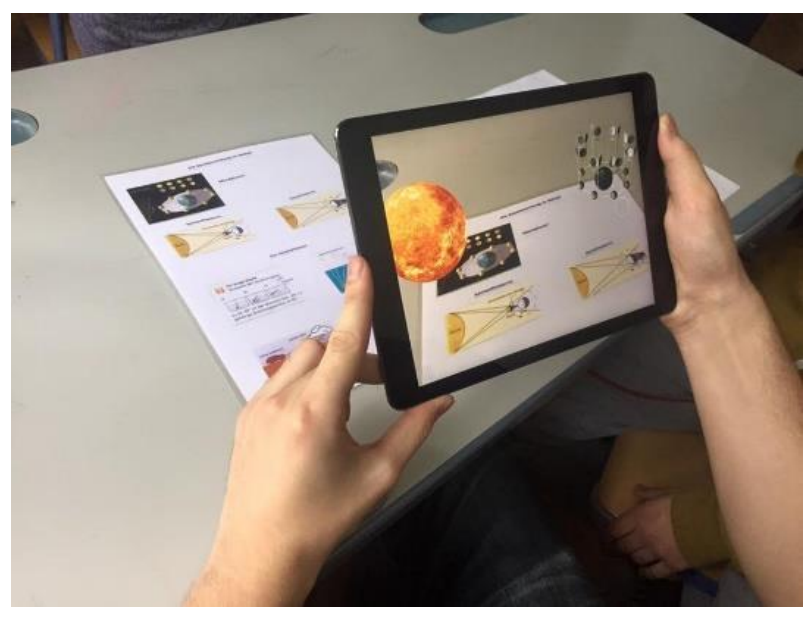

Şekil 12. Eğitim Sektöründe Artırılmış Gerçeklik (Figure 12. Augmented Reality in the Education Industry)

\subsubsection{Tip}

Tıp alanında bu teknoloji sayesinde tıp öğrencileri eğitimlerini bu ortamda alabilirler ve doktorlar hastalarıyla birebir uzaktan teşhis için etkileşime geçebilirler. Kritik durum ve zamanlarda tanı, tedavi ve müdahale planlarına yardımcı olur, tedavinin uygulandığı yere anında müdahale edebilirler.

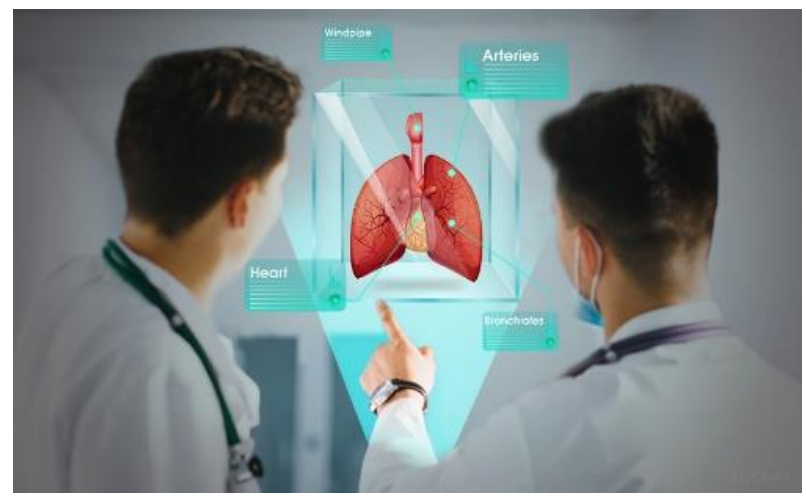

Şekil 13. Tıp Sektöründe Artırılmış Gerçeklik (Figure 13. Augmented Reality in the Medical Industry)

\subsection{Vuforia}

Unity ile geliştirilen bu çalışmada ilk aşamasında kullanılacak 3 boyutlu beyin cerrahisi alanında verilen derslerdeki beyin ile ilgili görsellerin oluşturulması yer alır. $\mathrm{Bu}$ görseller3dmax ile tasarlanmıştır. Çalışmaya eklenen $3 \mathrm{~d}$ resimler Unity editöründe Assets olarak isimlendirilmektedir. Unity editörü Asset Store uygulamasıyla ücretli/ücretsiz olarak 3 boyutlu görselleri çalışmamıza import ederek kullanmamızı sağlamaktadır. Çalışmamızdaki 3D tasarımlarından sonra bunların konumlandırılacağı yüzeyler seçilmelidir. $\mathrm{Bu}$ yüzeyler işaretçi(marker) olarak adlandırılan kamera bu görüntülere odaklandığı zaman 3D görseller ve yazılar üzerinde oluşacaktır. Marker yani işaretçi seçildikten sonra uygulamada oluşabilmesi için Vuforia Sdk geliştiricisi kullanılmıştır. Vuforia da bir çalışmayı oluşturabilmek için web sayfasından üyelik oluşturmamız gerekmektedir. Artırılmış Gerçeklikte çalışmalarımızı İlk aşamamızda yapılacak çalışmamız için Vuforia' nın resmi web sitesinden Develop kısmından Licence Key alt sekmesi kısmından "Key" oluşturmamız gerekmektedir. Oluşturulan "Key" çalışmamızın lisans anahtarı olacaktır, her çalışmamız için farklı oluşturulması gerekebilmektedir. İşaretçi olarak belirlediğimiz nesneyi Vuforia da tanımlarız. Bu nesneyi tanımlayabilmemiz için belli aşamalar vardır. İlk aşama olarak Vuforia' yaya yüklenen nesne değerlendirilir. Bu değerlendirme 5 yıldız alan nesne ile yapılan çalışma ve görüntüleme kalitesi iyi anlamındadır. Sistem işaretçinin ne kadar yıldız varsa o kadar yüksek oran ile işaretçiyi değerlendirir.

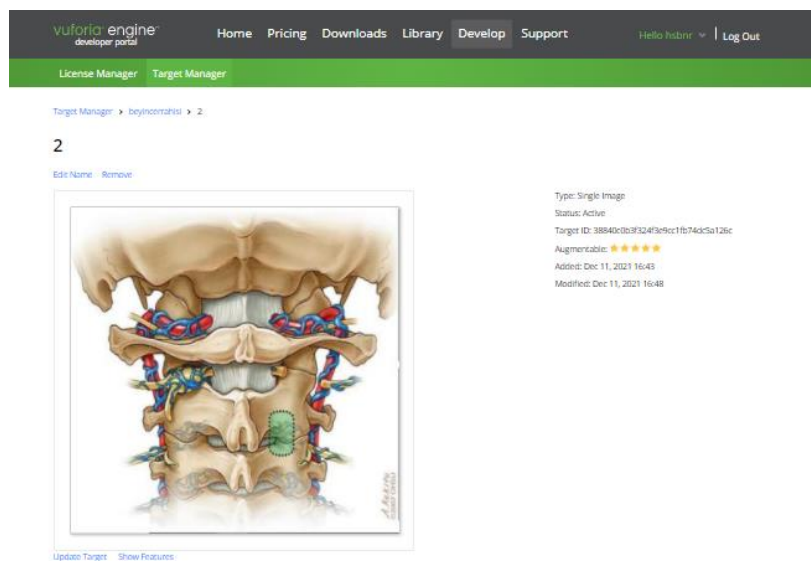

Şekil 14. Vuforia da Nesne İşaretçisi Ekleme (Figure 14. Adding an Object Pointer in Vuforia) 


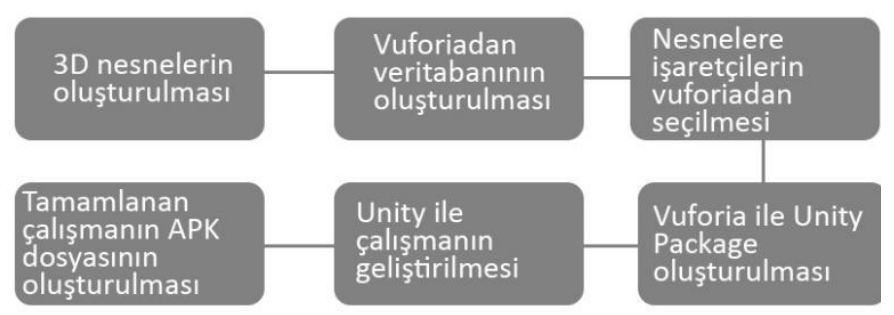

Şekil 15. Uygulama Aşamaları (Figure 15. Application Stages)

\section{Materyal ve Metot}

Bu çalışmada Konum ve İşaretçi Tabanlı Artırılmış Gerçeklik kullanılmıştır. Bu çalışma için yaygın olarak kullanılan Vuforia SDK kullanılmıştır. Geliştirme ortamı olarak Unity, Android Studio ve Visual Studio tercih edilmiştir. Vuforia SDK'nın Artırılmış Gerçeklik teknolojisiyle birlikte kullanılmıştır. Çalışmada geliştirilmiş olan uygulamanın genel kullanımı Ana ekran kısmında dokümanlar kısmı seçildiğinde derste işlenecek olan kısımları mobil cihazlardan okutarak $3 \mathrm{~d}$ nesnesi ve detaylı bilgileri çıkmaktadır ayrıca 3d nesnesini 360 tur döndürme, büyültme, küçültme işlemleri yapılmaktadır. Yani her açıdan öğrenmek istediği önemli noktaları görebilmektedir. Ameliyatlar kısmında ise beyin cerrahisinde yapılmış ameliyatların videoları ve çalışmaları yer almaktadır. Tıp öğrencisinin veya doktorun mobil cihazını görselin üzerine tutmasıyla bir ameliyattaymış gibi izlemesine olanak sağlamaktadır ve önemli bilgileri ve tecrübeleri kazanabilmektedirler.

\section{Araştırma Sonuçları ve Tartışma}

Beyin Cerrahisi alanında yapılmış bu çalışmanın kullanışlılığına yönelik bulgular incelendiğinde, tıp öğrencilerinin işaretleyicileri hareket ettirdiği durumlarda görüntü elde etme, video player, işaretleyicileri bulunması ve tanımlanması, kodların çözümlenmesi doğru olarak çalıştığı gözlemlenmiştir. Ayrıca bu çalışmada farklı teknolojik cihazlarda kullanabildiği için kullanımının daha kolay ve erişim daha hızlı olduğu gözlemlenmiştir. NFCI özellikli kartlara yüklenen bu uygulama ayrıca tıp öğrencilerine verilerek her zaman NFCI özelliği olan cihazlara okuttuğunda uygulamaya erişim sağladıkları belirtilmiştir.Ayrıca bu çalışmada Unity ve Artırılmış Gerçeklik aracıyla beyin cerrahisindeki eğitimlerde yer alan ders notlarında yer almayan bilgilerin kamerası olan herhangi bir mobil cihazla o noktaları okutarak tasarlanmış $3 \mathrm{~d}$ nesnelerini ve bilgilerini bu nesnelerde büyültme, küçültme ve rotate işlemlerini yaparak daha akılda kalması planlanmıştır.

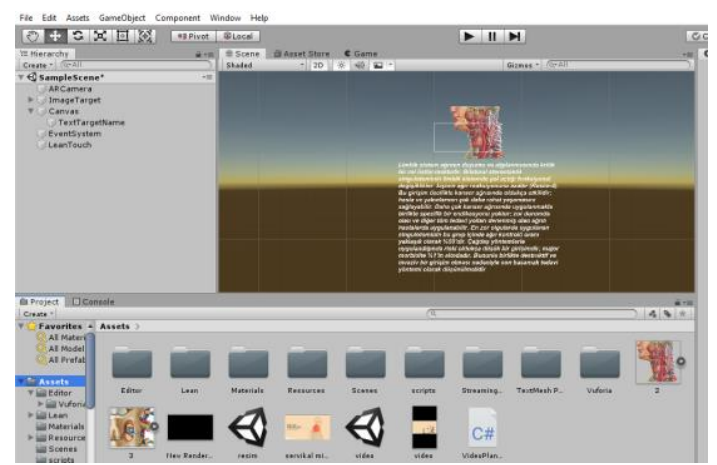

Şekil 16. Unity 3D Nesnenin Zoom ve Rotate İşlemleri (Figure 16. Zoom and Rotate Operations of Unity 3D Objects)

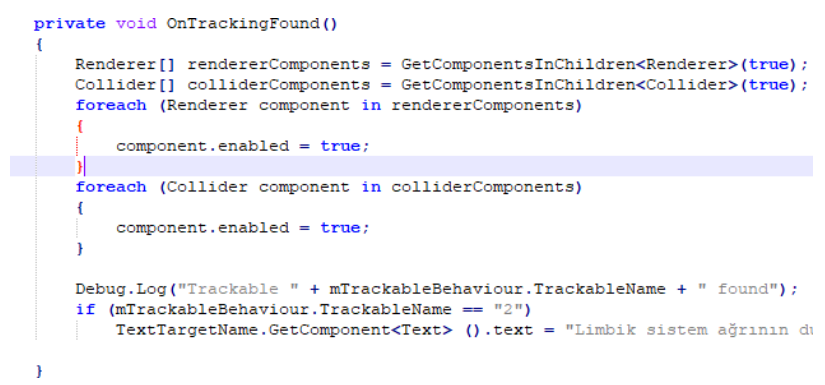

Şekil 17. Unity 3D Nesnenin Zoom, Rotate İșlemleri C\# Kod (Figure 17. Unity 3D Object Zoom, Rotate Operations C\# Code)

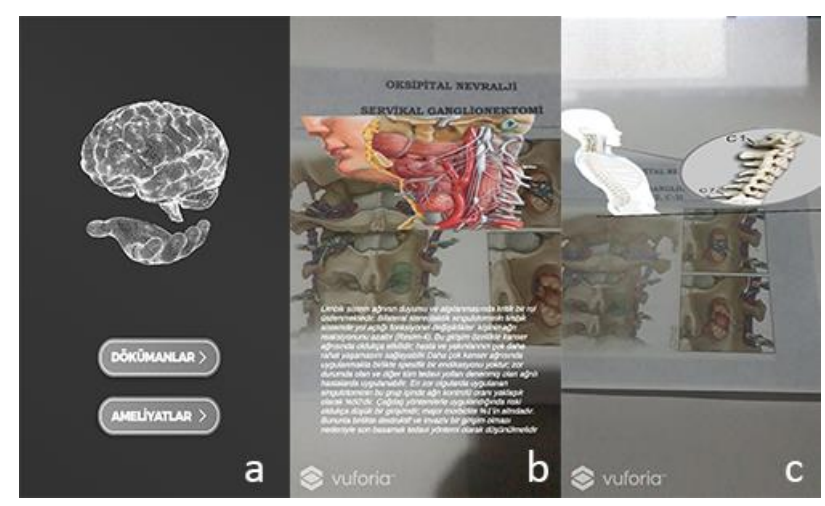

Şekil 18. Uygulamada Elde Edilmiş Veriler (Figure 18. Data Obtained in Practice)

Yukarıda verilmiş görselde a adımda uygulamaya giriş ekranı yer almaktadır. Burada dokümanlar ve ameliyatlar kısmı olarak 2' ye ayrılmaktadır. Dokümanlar kısmında derste işlenen bilgilerin detay açıklaması, 3 boyutlu görselleri, hastalardan alınmış röntgenler yer almaktadır. Ameliyatlar kısmında da beyin cerrahisi alanında yapılmış ameliyat videolarına ulaşılmaktadır. B ve $\mathrm{C}$ alanı dokümanlar kısmından ulaşılmaktadır.

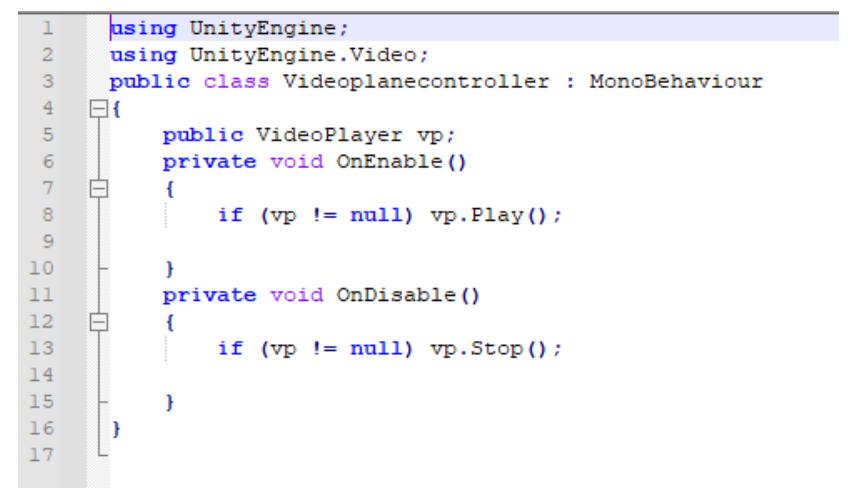

Şekil 19. Ameliyat Kısmındaki Derslerde Yer Alan Videoları Çalıştırma Kodu (Figure 19. Code to Run the Videos in the Lessons in the Surgery Section)

\section{Sonuç}

Sonuç olarak Artırılmış Gerçeklik kullanılarak oluşturulan uygulamada tıbbi kavram ve bilgilerin anlaşılmasını kolaylaştırmak bundan dolayı öğrenmenin etkisini de artırmaktadır. Artırılmış gerçeklik teknolojisi ile ameliyat kısımlarına, 3d resimlerine değinilerek öğrencilere daha keşifsel 
öğrenme deneyimi sunulmuştur. Böylece artırılmış gerçeklik teknolojisi ile ameliyatlar sırasında karşılaşılabilecek hatalar, hasta güvenliği için bir risk oluşturmamaktadır. Ayrıca öğrenci ve öğretici ihtiyaçlarına göre daha esnek bir yapıda kullanılabilir. $\mathrm{Bu}$ uygulama sadece bilgi almak olarak değil bu sistemi kullanan öğrenci ve öğreticilerin katkılarıyla, bilgisi alınan ameliyatlar ve ders bileşenleri hakkında geri bildirimler ile tıp öğrencilerine daha iyi bir eğitim verebilecektir. Günümüzde Covid-19 nedeniyle derslere ara verdiğimiz zamanlarda özellikle tıp eğitiminde bu tür uygulama sayesinde öğrencilerin deneyimlerini ve ders içeriklerini daha hızlı algılayabilmelerine yardımcı olacaktır.

\section{Teşekkür}

$\mathrm{Bu}$ çalışmamda her türlü yardımını esirgemeyen danışmanım Seydişehir Ahmet Cengiz Mühendislik Fakültesi Bilgisayar Mühendisliği Bölüm Başkanı Dr. Öğr. Üyesi Yusuf UZUN' a ve çalışmamım her aşamasında yanımda olan aileme sonsuz teşekkür ederim.

\section{Kaynakça}

Akkuş, İ., \& Özhan, U. (2017). Matematik ve Geometri Eğitiminde Artırılmış Gerçeklik Uygulamaları. Inonu University Journal of the Graduate School of Education, 19-31.

arimarsc. (2019). İmalat Sanayinde AR (Artırılmış Gerçeklik ) Uygulamalarının Getirdiği Faydalar. İmalat Sanayinde AR ( Artırılmış Gerçeklik ) Uygulamalarının Getirdiği Faydalar.

Bilban, M., 2020. Otonom araç üzerinde artırılmış gerçeklik uygulamas1. Yüksek Lisans Tezi, Necmettin Erbakan Üniversitesi Fen Bilimleri Enstitüsü, Konya, 57.

Bingöl, B. (2016). Yeni Bir Yaşam Biçimi: Artırılmış Gerçeklik(AG). Üsküdar Üniversitesi İletişim Fakültesi Akademik Dergisi, 44-55.

Çakal, M. A., \& Eymirli, E. (2012). Artrılmış Gerçeklik Teknolojisi. Artrılmış Gerçeklik Teknolojisi.

Çevik, G., Yılmaz, R. M., Göktaş, Y., \& Gülcü, A. (2017). Okul Öncesi Dönemde Artırılmış Gerçeklikle İngilizce Kelime Öğrenme. Journal of Instructional Technologies \& Teacher Education, 50-57.

Çiloğlu, T., Yılmaz, Ö., Yılmaz, A., \& Yılmaz, F. G. (2021). Eğitimde ArtırılmıG̣ Gerçeklik Konulu Makalelerin İncelenmesi. Ahmet Keleşoğlu Eğitim Fakültesi Dergisi, 147-158.

Doğan, A. (2016). Artırılmış Gerçeklik Teknolojileriyle Desteklenmiş Hikaye Kitabı Okuma Deneyimi. Tasarım ve Mimarlık Fakültesi Dergisi, 121-137.

Eginli, M. A., \& Nacaklı, Y. (2020). Uçak Bakım Eğitimlerinde Artırılmış Gerçeklik Kullanımının Değerlendirilmesi. Journal Of Aviation, 61-78.

Emre, Ş., Yolcu, M. B., \& Celayir, S. (2018). Çocuk Cerrahisi Öğrenci Eğitiminde Üç Boyutlu Modellerin Kullanılması: Süreç ve İlk İzlenimler. Çoc. Cer. Derg., 55-60.

Güçlü, H., 2021. Müzik eğitiminde artırılmış gerçeklik teknolojisi ve örnek uygulaması. Yüksek Lisans Tezi, Necmettin Erbakan Üniversitesi Fen Bilimleri Enstitüsü, Konya, 60.

Güneş, M., \& Dilipak, H. (2020). Ciddi Oyunların Hazırlaması ve Değerlendirilmesine Yönelik Bir Derleme
Makalesi. Gsi Journals Serie C: Advancements In Information Sciences And Technologies, 56-91.

İbili, E., \& Şahin, S. (2013). Artırılmış Gerçeklik ile İnteraktif 3D Geometri Kitabı Yazılımın Tasarımı ve Geliştirilmesi: ARGE3D. Afyon Kocatepe Üniversitesi Fen ve Mühendislik Bilimleri Dergisi, 1-8.

İçten, T., \& Bal, G. (2017). Artırılmış Gerçeklik Teknolojisi Üzerine Yapılan Akademik Çalışmaların İçerik Analizi. Bilişim Teknolojiler Dergisi, 401-415.

İçten, T., \& Bal, G. (2017). Artırılmış Gerçeklik Üzerine Son Gelişmelerin ve Uygulamaların İncelenmesi. Gazi Üniversitesi Fen Bilimleri Dergisi, 111-136.

Koşan, L. (2014). Muhasebe Eğitiminde Artırılmış Gerçeklik Uygulamaları. Çukurova Üniversitesi İIBF Dergisi, 37-47.

Küçük, S., Kapakin, S., \& Göktaş, Y. (2015). Tıp Fakültesi Öğrencilerinin Mobil Artırılmış Gerçeklikle Anatomi Öğrenimine Yönelik Görüşleri. Yükseköğretim ve Bilim Dergisi, 316-323.

Martlı, E. P., \& Dincer, N. (2020). Hemşirelik Eğitiminde Teknoloji: Artırılmış Gerçeklik. Pamukkale Üniversitesi Mühendislik Bilimleri Dergisi, 627-637.

Özdemir, M. (2017). Artırılmış Gerçeklik Teknolojisi ile Öğrenmeye Yönelik Deneysel Çalışmalar: Sistematik Bir İnceleme. Mersin Üniversitesi Eğitim Fakültesi Dergisi, 609-632.

Sabah, L., \& Şimşek, M. (2018). Arttırılmış Gerçeklik Yöntemleri İle Konumsal Mobil Kampüs Bilgi Sistemi. Düzce Üniversitesi Bilim ve Teknoloji Dergisi, 637-649.

Taçgın, Z., \& Taçgın, E. (2020). Akıllı Bir Çoklu Model Arttırılmış Gerçeklik Uygulaması Ameliyat Öncesi Prosedür Becerilerinin Öğretilmesi. Bilişim Teknolojileri Dergisi, 57-63.

Yılmaz, R. M., \& Göktaş, Y. (2018). Artırılmış Gerçeklik Teknolojisinin Eğitimde Kullanımı. Çukurova Üniversitesi Eğitim Fakültesi Dergisi, 510-537.

Yolcu, M. B., Emre, Ş., \& Celayir, S. (2018). Artırılmış Gerçekliğin Tıpta ve Çocuk Cerrahisinde Kullanımı. Çoc. Cer. Derg., 89-92.

Yöndem, T., \& Karadağ, G. H. (2019). Artırılmış Gerçeklikle Değişen Haber Sunumu. Yeni Medya Elektronik Dergi, 22-44.

Yüksekdağ, B. B. (2021). Sağlık Profesyonellerinin Eğitiminde Artırılmış Gerçeklik Uygulamaları. Açıköğretim Uygulamaları ve Araştırmaları Dergisi, 130-148. 